\title{
Shrinkage induced flow and Free surface evolution during solidification of pure metal
}

\author{
Aniket D. Monde ${ }^{1}$, Anirban Bhattacharya ${ }^{2}$, and Prodyut R. Chakraborty ${ }^{1, *}$ \\ ${ }^{1}$ Department of Mechanical Engineering, IIT Jodhpur, 342037, India \\ ${ }^{2}$ Department of Mechanical Engineering, IIT Bhubaneswar, 752050, India
}

\begin{abstract}
A numerical model is developed to study Shrinkage induced convection and free surface evolution caused by the density difference between the solid and liquid phases during the solidification of pure aluminium. For the analysis, a 2-D rectangular cavity field with aluminium melt undergoing solidification process is considered. Conservation of mass, momentum, and energy are formulated based on volume averaging technique and are solved using the SIMPLER algorithm. The free surface evolution is captured using the Volume of fluid (VOF) method. The proposed model focuses on predicting macro-scale shrinkage induced surface defects during the solidification process.
\end{abstract}

\section{Introduction}

Phase change process is extensively confronted in many practical applications such as manufacturing processes involving metal casting and welding, latent heat thermal storage, thermal sprays, etc. Appreciable contribution towards developing numerical and analytical models to investigate the convection and heat transfer during the solidification by several research groups can be identified in the existing literature [1-6]. Incremental efforts are made to study the effects of shrinkage because of complications involving multiphase pressurevelocity coupling and the free surface evolution during solidification process [7-13].

Among the existing literature, Chiang et al. [7] proposed a shrinkage model based on the volume averaged continuum equations developed by Bennon and Incropera [1]. However, the source term corresponding to natural convection was neglected during the bottom cooling analysis. Furthermore, numerical and experimental investigations were performed $[11,12]$ to study solidification shrinkage and macro-segregation.

None of these existing predictions involve enthalpy updating scheme to evaluate solid and liquid volume fractions $[3,6]$. The present study focuses on finding the validity of enthalpy updating scheme in the existing framework, where shrinkage induced convection and free surface evolution can be captured by the model without applying any superficial numerical treatment.

\section{Analysis and Modelling}

For the present numerical study, the cavity geometry is similar to the one reported by Chiang et al. [7] and is shown in Figure 1. The cavity geometry for the first case study consists of a rectangular cavity attached with a riser at the top. The second case study deals with a cavity without a riser. The domain is initially filled with liquid aluminium, at a temperature above its melting point $\left(\mathrm{T}_{\mathrm{i}}>\mathrm{T}_{\mathrm{m}}\right)$. Solidification commences by reducing the temperature of walls below its melting point $\left(\mathrm{T}_{\mathrm{s}}<\mathrm{T}_{\mathrm{m}}\right)$. For both cases, the free surface is assumed to be adiabatic. The conservation equation for mass, momentum, energy, and advection are given as follows $[1,7]$ :

Continuity

$$
\frac{\partial}{\partial t}(\rho)+\nabla \cdot(\rho V)=0
$$

Momentum

$$
\begin{aligned}
& \frac{\partial}{\partial \mathrm{t}}(\rho \mathrm{u})+\nabla \cdot(\rho \mathrm{Vu}) \\
&=\nabla \cdot\left(\mu_{\mathrm{l}} \frac{\rho}{\rho_{\mathrm{l}}} \nabla \mathrm{u}\right)-\frac{\partial \mathrm{p}}{\partial \mathrm{x}}-\frac{\mu_{\mathrm{l}}}{\mathrm{K}} \frac{\rho}{\rho_{\mathrm{l}}} \mathrm{u}-\nabla \cdot\left(\rho \frac{\mathrm{g}_{\mathrm{s}} \rho_{\mathrm{S}}}{\mathrm{g}_{\mathrm{l}} \rho_{\mathrm{l}}} \mathrm{Vu}\right) \\
&+\nabla \cdot\left(\mu_{\mathrm{l}} \mathrm{u} \nabla\left(\frac{\rho}{\rho_{\mathrm{l}}}\right)\right) \\
& \frac{\partial}{\partial \mathrm{t}}(\rho \mathrm{v})+\nabla \cdot(\rho \mathrm{Vv})= \nabla \cdot\left(\mu_{\mathrm{l}} \frac{\rho}{\rho_{\mathrm{l}}} \nabla \mathrm{v}\right)-\frac{\partial \mathrm{p}}{\partial \mathrm{y}}-\frac{\mu_{\mathrm{l}}}{\mathrm{K}} \frac{\rho}{\rho_{\mathrm{l}}} \mathrm{v}-\nabla \cdot\left(\rho \frac{\mathrm{g}_{\mathrm{s}} \rho_{\mathrm{S}}}{\mathrm{g}_{\mathrm{l}} \rho_{\mathrm{l}}} \mathrm{Vv}\right) \\
&+\nabla \cdot\left(\mu_{\mathrm{l}} \mathrm{V} \nabla\left(\frac{\rho}{\rho_{\mathrm{l}}}\right)\right) \\
&+\rho_{\mathrm{ref}}^{1} \mathrm{~g}_{\mathrm{a}} \beta\left(\mathrm{T}_{\text {mean }}-\mathrm{T}_{\mathrm{ref}}\right)
\end{aligned}
$$

Energy

$$
\begin{aligned}
\frac{\partial}{\partial \mathrm{t}}(\rho \mathrm{T})+\nabla \cdot(\rho \mathrm{VT})= & \nabla \cdot\left(\frac{\mathrm{k}}{\mathrm{C}_{\mathrm{ps}}} \nabla \mathrm{T}\right)-\left(\frac{\mathrm{c}_{\mathrm{pl}}}{c_{\mathrm{ps}}}-1\right) \nabla \cdot(\rho \mathrm{VT}) \\
& -\frac{\rho_{\mathrm{s}} \mathrm{h}_{\mathrm{sl}}}{\mathrm{c}_{\mathrm{ps}}} \frac{\partial}{\partial \mathrm{t}}\left(\mathrm{g}_{1}\right)-\left(\frac{\mathrm{c}_{\mathrm{pl}}}{c_{\mathrm{ps}}}-1\right) \frac{\partial}{\partial \mathrm{t}}\left(\mathrm{g}_{\mathrm{l}}\left(\rho_{\mathrm{l}} \mathrm{T}-\rho_{\mathrm{s}} \mathrm{T}_{\mathrm{m}}\right)\right) \\
& -\left(\frac{\rho_{s} \mathrm{~h}_{\mathrm{sl}}}{\mathrm{c}_{\mathrm{ps}}}\right. \\
& \left.-\rho_{\mathrm{s}} \mathrm{T}_{\mathrm{m}}\left(\frac{\mathrm{c}_{\mathrm{pl}}}{\mathrm{c}_{\mathrm{ps}}}-1\right)\right) \frac{\partial}{\partial \mathrm{t}}\left(\mathrm{g}_{\mathrm{v}}\right)
\end{aligned}
$$

Corresponding author: pchakraborty@,iitj.ac.in 


$$
\frac{\partial}{\partial \mathrm{t}}\left(\mathrm{g}_{\mathrm{v}}\right)+\nabla \cdot\left(\mathrm{g}_{\mathrm{v}} \mathrm{V}\right)-\mathrm{g}_{\mathrm{v}}(\nabla \cdot \mathrm{v})=0
$$

The above conservation equations are derived on the basis that the $\mathrm{V}_{\mathrm{s}}=0, \rho_{\text {void } / \text { air }} \ll \rho_{s / l}$ and $\mathrm{k}_{\mathrm{void} / \text { air }} \ll$ $\mathrm{k}_{\mathrm{s} / \mathrm{l}}$, thus were neglected. The significance of each term in the momentum equation is detailed in $[1,7]$. The term $K$ appearing in Darcian damping force source term is defined as,

$$
\mathrm{K}=\mathrm{K}_{0}\left(\frac{\mathrm{g}_{\mathrm{l}}^{3}+\epsilon}{\left(1-\mathrm{g}_{\mathrm{l}}\right)^{2}}\right)
$$

where $\mathrm{K}_{0}$ is permeability constant and $\epsilon$ is very small number $\left(\sim 10^{-10}\right)$.

All the three phases, solid-liquid phase change system, and void system are considered. Thus along with liquid volume fraction $\left(g_{l}\right)$, void volume fraction $\left(g_{v}\right)$ appears within last term in right side of energy equation.

The boundary conditions for the momentum and energy equations to be solved for the symmetric domain (Fig. 1(b)) are defined as: (i) at free surface:- $\partial \mathrm{u} / \partial \mathrm{y}=0$, guage pressure $\mathrm{p}=0, \partial \mathrm{T} / \partial \mathrm{y}=0$; (ii) at symmetric axis:- $\mathrm{u}=0, \partial \mathrm{v} / \partial \mathrm{x}=0, \partial \mathrm{T} / \partial \mathrm{x}=0$; (iii) bottom wall:$\mathrm{u}=0, \mathrm{v}=0, \mathrm{~T}=\mathrm{T}_{\mathrm{b}}$; and (iv) at remaining walls:$\mathrm{u}=0, \mathrm{v}=0$, case 1:- walls are insulated, case 2:$\mathrm{T}=\mathrm{T}_{\mathrm{b}}$.

The governing equations are discretised to obtain system of linear algebraic equations and are solved iteratively for each time step using finite volume method [14]. To track the solid-liquid interface, a volume fraction updating scheme was implied as proposed in $[3,6]$.

\section{Results and Discussion}

Numerical investigation was performed using properties of Aluminium and are mentioned in Table 1 with casting and geometrical data. Two case studies are performed with and without riser respectively, to examine free surface deformation.

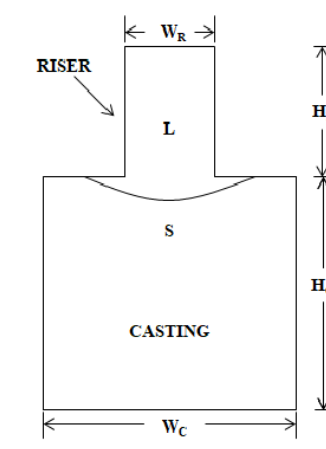

(a)

Fig. 1. Schematic of the (a) physical domain of interest and (b) domain used during the computation.

Table 1. Material properties of Aluminium, casting condition and geometrical data

\begin{tabular}{cc}
\hline$k_{l}=90.7 \mathrm{~W} / \mathrm{mK}$ & $k_{s}=211 \mathrm{~W} / \mathrm{mK}$ \\
$c_{p l}=1087 \mathrm{~J} / \mathrm{kgK}$ & $c_{p s}=1087 \mathrm{~J} / \mathrm{kgK}$ \\
$\rho_{\mathrm{l}}=2370 \mathrm{~kg} / \mathrm{m}^{3}$ & $\rho_{\mathrm{s}}=2535 \mathrm{~kg} / \mathrm{m}^{3}$ \\
$h_{s l}=398000 \mathrm{~J} / \mathrm{kg}(*)$ & $\beta=0.000021 \mathrm{~K}^{-1}(*)$ \\
$\mu=0.00138 \mathrm{~kg} / \mathrm{ms}$ & $T_{m}=933.2 \mathrm{~K}$
\end{tabular}

$$
\begin{array}{cr}
T_{i}=1073 \mathrm{~K} & T_{b}=300 \mathrm{~K} \\
W_{C}=0.2 \mathrm{~m} & H_{C}=0.15 \mathrm{~m} \\
W_{R}=0.05 \mathrm{~m} & H_{R}=0.075 \mathrm{~m} \\
\text { *-assumed }
\end{array}
$$

\section{Case1:- Riser at the top and bottom cooling $\left(T_{b}\right)$}

The convection currents developed with free surface movement due to shrinkage is shown in Fig. 2 at different times for bottom cooling at $300 \mathrm{~K}$. From the results, it can be observed that the velocity magnitude at the start of solidification is maximum at the top of the riser. This leads to formation of primary convection within the casting. From Fig. 2(a), it can be observed that the flow coming in from the riser expanding (curving away) in transverse direction and interacts with the interface with lesser inertia. The transverse expansion of shrinkage induced flow from the riser can be attributed to the resistance due to buoyancy force inside the cavity adjacent to the riser. The stably stratified liquid inside the cavity does not allow the hot lighter liquid coming in from the riser to straightaway penetrate itself. As the solidification progresses in time, the curving primary flow causes a pair of complementary convection loops characterized upward motion at the centre of the cavity Fig. 2(b).

During the solidification, the free surface movement is 1-D within the riser, and it is flat surface. However, at the end of the solidification, the surface attains a dimpled shape which can be attributed to the conservation of mass Fig. 2(c). From these results we conclude that the present numerical model is capable of capturing the interface growth as well as free surface movement.

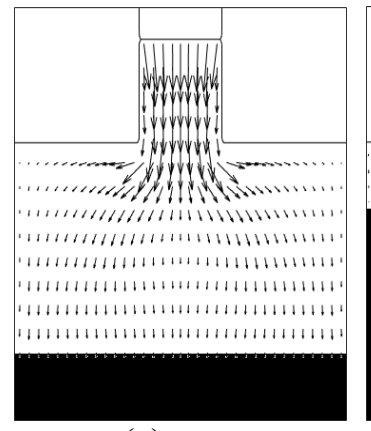

(a)

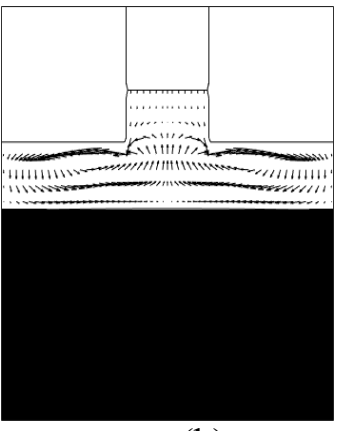

(b)

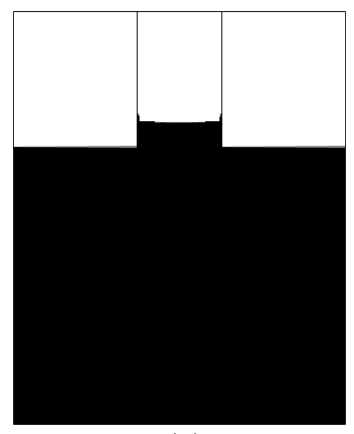

(c)

Fig. 2. Stated flow convection, solidification growth, and free surface movement at times (a) $10 \mathrm{~s} \mathrm{(b)} 100 \mathrm{~s}$ and (c) $200 \mathrm{~s}$ for $T_{b}=300 K$. 


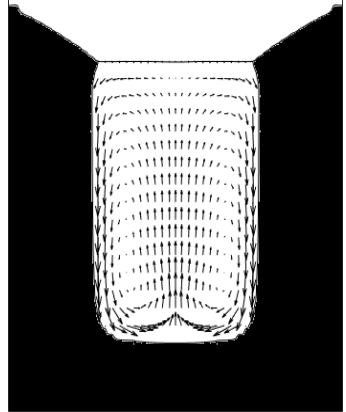

(a)

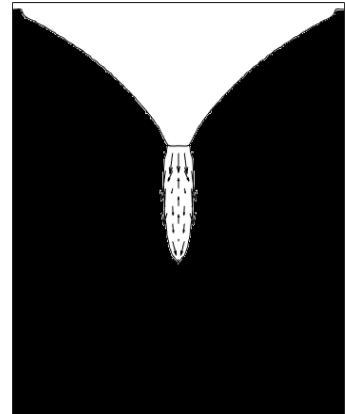

(b)

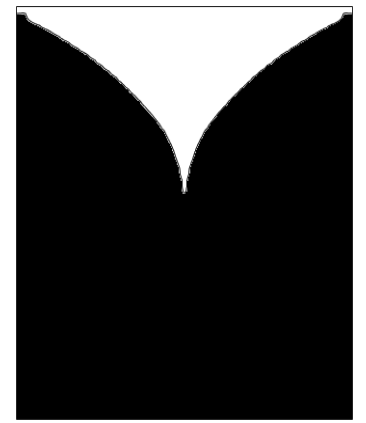

(c)

Fig. 3. Free surface movement at times (a) $10 \mathrm{~s}$ (b) $30 \mathrm{~s}$ and shrinkage cavity formation at time (c) 40 s.

\section{Case2:- Mould cavity}

For the open mould cavity analysis, the riser portion is discarded keeping the top portion open and the other dimensions to be same as mentioned in Table 1. Cooling is ensued from the bottom and side walls by maintaining the temperature of walls to $300 \mathrm{~K}$ and it is assumed that no heat is dissipated to the atmosphere through free surface. Fig. 3 shows the predicted numerical results of the position of free surface, flow convection and solidified domain at times $10 \mathrm{~s}, 30 \mathrm{~s}$, and $40 \mathrm{~s}$.

It can be observed that solidification growth ensues from all the three sides of the mould cavity defining a shrinkage induced shape of the solid front. As solidification proceeds, the shallow patch of the melt at the centre contracts continuously and the flat liquid-void free surface advances in the downward direction. At the end of the solidification, the deformed surface of the casting has a V-shaped depression. The depression obtained is vitally controlled by the casting condition applied at the walls.

\section{Conclusions}

An enthalpy updating scheme based solidification model is formulated to capture the shrinkage induced convection and evolution of free surface. The proposed model is applied to predict the free surface evolution and shrinkage defect of the final cast product during solidification of pure aluminium under isothermal cooling boundary condition. The numerical predictions are found to be physically consistent in terms of shape of the shrinkage defect in the final cast product. The case study involving riser and bottom cooling condition reveals that buoyancy source term has significant effect on defining the shrinkage induced flow pattern. The buoyancy effect opposes and dampens the shrinkage induced flow from the riser, and produces a pair of counter rotating convection loops having a net upward motion along the line of symmetry of the 2-D cavity.

\section{References}

1. W.D. Bennon, F.P. Incropera, Int. J. Heat Mass Transf., 1987, vol. 30, pp. 2161-2170.

2. W.D. Bennon, F.P. Incropera, Int. J. Heat Mass Transf., 1987, vol. 30, pp. 2171-2187.

3. V.R. Voller, C. Prakash, Int. J. Heat Mass Transf., 1987, vol 30, pp. 1709-1719.

4. V.R. Voller, Int. J. Heat Mass Transf., 2008, vol. 51, pp. 823-834.

5. A. Bhattacharya, P. Dutta, Int. J. Numer. Methods Heat Fluid Flow, 2013, vol. 23, pp. 1121-1135.

6. P.R. Chakraborty, Int. Commun. Heat Mass Trans., 2017, vol. 81, pp. 183-189.

7. K.C. Chiang, H.L. Tsai, Int. J. Heat Mass Transf., 1992, vol. 35, pp. 1763-1770.

8. S. Bounds, G. Moran, K. Pericleous, M. Cross, T.N. Croft, Metall. Mater. Trans. B, 2000, vol. 31, pp. 515-527.

9. T. Wang, M. Wu, A. Ludwig, M. Abondano, B. Pustal, A. Bu «hrig-Polaczek, 2005. Int. J. Cast Meta. Res., 2005, vol. 18, pp. 221-22

10. M. Raessi, J. Mostaghimi, Numer. Heat Transf., Part B: Fundam., 2005, vol. 47, pp. 507-531.

11. D. Sun, S.V. Garimella, Numer. Heat Transf., Part A: Appli., 2007, vol. 52, pp. 145-162.

12. H. Ge, F. Ren, J. Li, X. Han, M. Xia, J. Li, Metall. Mater. Trans. A, 2017, vol. 48, pp. 1139-1150.

13. D.B. Kothe, R.C. Mjolsness, M.D. Torrey, Avail. DOE DOE contrac. OSTI, 1991.

14. S. Patankar, Numer. Heat Transf. Fluid Flow. 1980, CRC press. 